\title{
O ENSINO DE LITERATURA: PERSPECTIVAS COMPARATISTAS E A FORMAÇÃO DE PROFESSORES À LUZ DA LEI 11.645/08
}

Rosangela Sarteschi'

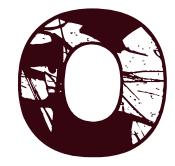

presente texto tem por objetivo fazer uma breve reflexão conceitual e teórica sobre a formação dos futuros professores do componente curricular "Língua Portuguesa" da rede pública e privada da educação básica no âmbito da área dos Estudos Comparados de Literaturas de Língua Portuguesa, do Departamento de Letras Clássicas e Vernáculas da Faculdade de Filosofia, Letras e Ciências Humanas da USP.

Com a reformulação da Licenciatura proposta pela LDB e impulsionada pelo Parecer 09/2001, do Conselho Nacional de Educação, constituiu-se na USP, nesse mesmo ano, a Comissão Permanente de Licenciatura, no âmbito do Programa de Formação de Professores, que buscou articular - dentre os diferentes cursos da Universidade - uma unificação de princípios e diretrizes para a formação de professores.

As diferentes licenciaturas da USP, antes restritas à Faculdade de Educação, passaram, a partir de 2008, a ser pensadas e estruturadas, nos Institutos e Faculdades, de modo a contribuir de maneira mais preponderante para o processo formativo dos futuros docentes. Nesse sentido, a Faculdade de Filosofia, Letras e Ciências Humanas passou, então, a oferecer as chamadas disciplinas de interface entre conteúdos específicos e pedagógicos com o objetivo de possibilitar aos estudantes um contato mais aprofundado com temas e conteúdos necessários à formação do professor nas diversas áreas da Faculdade. No caso do curso de Letras, passou-se a oferecer dez disciplinas com o objetivo de cumprir esse princípio. São elas: Literatura e Educação (oferecida pelo Departamento de Teoria Literária e Literatura Comparada; Língua, Discurso e Ensino, Ensino da Literatura Brasileira, Literatura Portuguesa: Ensino e Aprendizagem, Diversidade Cultural e Educação: as literaturas 1 Professora Doutora da Área de Estudos Comparados de Literaturas de Língua Portuguesa 
de língua portuguesa em perspectiva (todas oferecidas pelo Departamento de Letras Clássicas e Vernáculas); Aquisição/Aprendizagem do Alemão como Língua Estrangeira, Literaturas Hispânicas: Processos Históricos e Perspectivas Teórico-Críticas, Abordagens Críticas e o Ensino de Literatura (da Habilitação de Inglês), Aquisição/Aprendizagem do Francês como Língua Estrangeira, Ensino e Aprendizagem da Língua Italiana (no âmbito do Departamento de Letras Modernas). É necessário destacar ainda o oferecimento, a todas as licenciaturas da Universidade, do curso de Libras (Língua Brasileira de Sinais) sob responsabilidade do Departamento de Linguística.

É nesse contexto que a nossa área - Estudos Comparados de Literaturas de Língua Portuguesa - idealizou a disciplina Diversidade cultural e educação: as literaturas de língua portuguesa em perspectiva e a respectiva "Atividades de Estágio", tendo, além dos já mencionados, o objetivo específico de fornecer subsídios teóricos e práticos para que, por meio da abordagem comparativa das literaturas de língua portuguesa, os alunos possam refletir sobre o ensino da literatura em geral e, mais especificamente, sobre a aplicação da Lei 11.645/08 (texto que modificou a Lei 10.639/03) nos currículos do ensino básico, que prevê a inclusão de temas relacionados à história e cultura africana, afro-brasileira e indígena nos currículos escolares. Além disso, pretende ainda contribuir para a formação de futuros professores para que sejam capazes de atuar pedagogicamente no combate à discriminação cultural e étnico-racial.

Feitas essas considerações de caráter mais institucional, mas importantes para contextualizar o processo de formação de professores tal qual é atualmente praticado no curso de Letras da USP, passaremos a abordar questões conceituais a partir da perspectiva dos estudos comparatistas das literaturas de língua portuguesa e as especificidades inerentes a esse campo de estudo e também como método de problematização do literário.

Assim, pensar pedagogicamente no conjunto da produção cultural produzida em língua portuguesa significa considerar, sobretudo, a 
configuração de um espaço identitário permeado por tensões e diferenças. Consideramos que aproximar tais literaturas entre as quais se colocam macroquestões diacrônicas e particularidades tão pronunciadas, é que torna não apenas o processo de formação de professores, mas também do ensino de literatura na escola básica ainda mais consistente, porque se colocam ao futuro professor questões como a que ressalta a pesquisadora carioca Laura Padilha:

É necessário reiterar o fato histórico cultural de que, pelo uso comum de "nossa língua", se cria um fecundo espaço de muitas possibilidades de entendimento no qual igualmente proliferam muitas cumplicidades e inúmeras histórias entrelaçadas. Contudo, faz-se também necessário, para que o entendimento, as cumplicidades e as histórias se consolidem mais e mais, que se construa um outro modo de ler e ver a trama das diferenças, para que elas, igualmente, se possam ler e ver sem elisões ou apagamentos impostos por qualquer hegemonia de ordem histórica, simbólica e, sobretudo, político-cultural. (PADILHA, 2005, p. 25)

Em outras palavras, os agentes envolvidos no processo com esse contorno pedagógico e também ideológico têm a oportunidade de entrar em contato com textos que trazem uma forma de pensar diversa da sua e serem, assim, capazes de analisá-los e problematizá-los em conjunto, mas compreendendo que cada um deles é composto de uma pauta e um desenvolvimento, com suas formações e lógicas internas, espelhando um sistema de reflexão externo, todas elas interagindo e coexistindo entre si.

A literatura ganha sentido porque se estabelece como uma possibilidade concreta de apreender o mundo e, no processo de leitura que se coloca, estão dadas as condições de interpretar as sociedades em que cada texto ou série literária estão inseridos. Esse é caso específico dos países africanos de língua oficial portuguesa, por exemplo, cuja característica determinante nos textos produzidos recai sobre o fato de a literatura, na história desses espaços, definir-se como um instru- 
mento relevante de transformação social. A existência de uma prolongada política de intensificação das diferenças entre os variados grupos etnolinguísticos fez e faz com que escritores cultivassem e cultivem suas possibilidades de costurar uma unidade, ainda que muitas vezes tênue, reconhecendo-lhe a função de aglutinar os fragmentos gerados pela história construída numa sequência de cisões.

Pode-se afirmar, então, que em todos os territórios africanos colonizados por Portugal, a produção literária chamada nacional nasce sob o signo da reivindicação, trazendo para si a função de participar do esforço de construir um espaço de discussão sobre a condição colonial: é notável, particularmente entre os romancistas, o desejo de reescrever o passado das sociedades em formação. Com vínculos fortes com a História, a Literatura funciona como um espelho dinâmico das convulsões vividas por esses povos, como afirma Rita Chaves (2005).

Alinhadas a essa postura estética e ética podemos citar obras como A Vida Verdadeira de Domingos Xavier ou Nós, os do Makulusu, de Luandino Vieira, Mayombe, de Pepetela (todos romances angolanos), os sete contos compilados em Nós Matámos o Cão Tinhoso, do moçambicano Luís Bernardo Honwana, entre outros.

Comparar essa produção com a brasileira, permitirá ao jovem professor e, na sequência, aos estudantes da educação básica, atentar para o próprio estatuto de país colonizado do Brasil e para as marcas profundas dessa condição que caracterizam, com maior ou menor intensidade, a produção cultural e literária do país. Além disso, questões tão complexas e controversas como a miscigenação racial e cultural poderão ser abordadas desde outra perspectiva em que se problematize o processo colonial português em relação à escravidão, à violência da relação entre colonizador e colonizado e às suas consequências na nova sociedade como as estruturais desigualdades sociais e raciais que perduram ainda hoje no Brasil.

Por meio dos diferentes textos literários - brasileiros, africanos e também portugueses - há a possibilidade de olhar para o passado com 
a finalidade de reelaborá-lo, apreendendo que a perspectiva de que aquela história que foi construída pelo poder metropolitano só é hegemônica porque baseada nas forças do colonialismo e do capitalismo.

Selecionar textos que dialoguem entre si, expondo dialeticamente as contradições, descontinuidades e rupturas propiciarão a oportunidade de participação ativa em um processo em que o ato de leitura seja muito mais do que mera fruição sem maiores compromissos e responsabilidades, já que, segundo entendemos, o leitor destinatário de toda criação literária é também introjetado pela obra que a ele se dirige, convertendo-se em texto e tomando a feição de um sujeito com o qual se estabelece um diálogo latente, mas necessário e repleto de significação e sentido. O leitor apresenta-se, nessa equação, também como sujeito do processo com o qual todo escritor depara-se continuamente.

Outra categoria a ser explicitada nessa instância é o discurso, que não se apresenta como um conjunto mais ou menos aleatório de textos, mas como prática constituída por ideologia. Como lembra Eni Orlandi $(1998,13)$, o sentido nunca está sozinho, não se produz de uma vez, em um só lugar e não é linear: por meio das relações que estabelece é que o sentido se faz sentido.

Nesse aspecto ler é interpretar, é produzir sentidos relacionados com outros sentidos e é na materialidade da língua que se engendra esse processo de contínua significação. $O$ ato de ler pode ser compreendido, então, como uma prática social, algo que se inscreve na dimensão simbólica das atividades humanas. Ao produzir leitura, o sujeito se engaja na dinâmica do processo histórico-social de produção de sentidos e torna-se assim um cidadão que esteja apto a intervir na sociedade de modo a transformá-la.

Assim, comparar textos a partir dessa perspectiva torna possível compreender que, no caso das literaturas brasileira e das africanas de língua oficial portuguesa, ocorreu um processo típico resultante da problematização do colonialismo entre elas e a literatura da metrópole.

Nesse confronto, percebeu-se rapidamente que a cultura e a literatura teriam papel decisivo na resistência ao poder colonial a fim de as 
ex-colônias manterem vivas suas tradições culturais. Por conseguinte, o que se observa não é a aniquilação de todos os traços culturais dos colonizados. O contato que ocorre entre portugueses e (ex-)colonizados resulta em uma outra cultura que contém marcas da cultura do dominado, anterior à chegada do invasor, e marcas da cultura que lhe foi trazida em processos de profunda violência, baseados na usurpação e na pilhagem. Esse fenômeno, denominado de processo de transculturação por Ángel Rama, demonstra a capacidade que uma determinada sociedade tem de elaborar uma cultura original, mesmo sob circunstâncias as mais adversas a que tenha sido submetida, em que se percebe a existência de uma energia criadora que atua com desenvoltura a partir da herança particular e das incidências provenientes do exterior.

Nesse sentido, Rama propõe:

uma figura em que as duas formas contrastadas geram três focos de ação em que se conjugam de modo diferente: haveria, pois, destruições, reafirmações e absorções, a que caberia acrescentar que esse processo, que no campo cultural teria uma alta porcentagem de determinismo, mostraria no campo literário uma margem elevada, proporcionalmente de liberdade, que se manifesta na capacidade relativa que 0 criador continuaria manejando. (RAMA, 2001, p. 217)

Entendemos, pois, que ocorre processo semelhante entre a literatura portuguesa e as literaturas africanas de língua portuguesa e também a brasileira: surge nesses espaços uma terceira cultura que vai buscar em sua tradição elementos de composição sem, no entanto, descartar contribuições europeias.

Dessa maneira, reiteramos que o trabalho de problematização e interpretação de textos literários a partir dos estudos comparatistas ganha profundidade, porque serão entendidos para além de qualquer setorização circunscrita no interior de uma única série literária. No caso das relações colocadas entre metrópole e ex-colônias, percebe-se cla- 
ramente que a literatura produzida nos espaços de dominação ilumina textos metropolitanos, alargando-lhes os significados.

Nessa mesma linha de entendimento, Edward Said sugere que:

a leitura e a interpretação dos grandes textos culturais metropolitanos, assim reformulados e ativados por uma nova perspectiva, não existiriam sem os movimentos de resistência que ocorreram por todas as partes das periferias contra o império [...] E hoje escritores e estudiosos do mundo ex-colonizado têm imposto suas diversas histórias, têm mapeado suas geografias locais nos grandes textos canônicos do centro europeu. E dessas interações sobrepostas, mas divergentes, estão começando a aparecer as novas leituras e conhecimentos. (SAID, 1995, p. 89)

Vemos ainda que as literaturas chamadas periféricas, escritas na língua do colonizador, trouxeram à baila questionamentos e problematizações do processo colonial bastante inquietantes e que estão longe de um equacionamento unânime. Bons exemplos dessa abordagem surgem no texto ensaístico do angolano Manuel Rui e também em vários poemas do brasileiro Oswald de Andrade, que, lidos em perspectiva, contribuem para uma elaboração de mundo mais crítica e autônoma:

Quando chegaste mais velhos contavam estórias. Tudo estava no seu lugar. A água. O som. A luz. Na nossa harmonia. O texto oral. E só era texto não apenas pela fala mas porque havia árvores, paralelas sobre o crepitar de braços da floresta. E era texto porque havia gesto.

Texto porque havia dança. Texto porque havia ritual. Texto falado ouvido e visto. É certo que podias ter pedido para ouvir e ver as estórias que os mais velhos contavam quando chegastes! Mas não! Preferiste disparar os canhões. 
A partir daí, comecei a pensar que tu não eras tu, mas outro, por me parecer difícil aceitar que da tua identidade fazia parte esse projeto de chegar e bombardear o meu texto. Mas tarde viria a constatar que detinhas mais outra arma poderosa além do canhão: a escrita.

E que também sistematicamente no texto que fazias escrito intentavas destruir o meu texto ouvido e visto. Eu sou eu e a minha identidade nunca a havia pensado integrando a destruição do que não me pertence.

(RUI apud MEDINA, 1987, p. 308)

MEDO DA SENHORA

A escrava pegou a filhinha nascida

Nas costas

E se atirou no Paraíba

Para que a criança não fosse judiada

(ANDRADE, 1971, p. 94)

LEVANTE

Contam que houve uma porção de enforcados

E as caveira espetadas nos postes

Da fazenda desabitada

Miavam de noite

No vento do mato

(ANDRADE, 1971, p. 94)

AZORRAGUE

- Chega! Peredoa!

Amarrados na escada

A chibata preparava os cortes

Para a salmoura

(ANDRADE, 1971, p. 95) 
Como se pode observar por meio da leitura desses textos, a questão da dominação colonial e suas complexas apreensões nos espaços anteriormente colonizados são reveladas, demonstrando no processo suas divergências e similitudes tanto estética quanto eticamente: são textos que propiciam muitas reflexões sobre os efeitos materiais da condição histórica do colonialismo e das consequências e significados do encontro colonial.

A reflexão acerca das relações existentes entre as produções literárias e culturais dos países de língua portuguesa aponta, como estamos procurando manifestar, para questões de nacionalidade, identidade, trocas culturais, sentido, valor, cânone, universalidade, diferença, hibridismo, etnicidade, zona de contato, hegemonia e diversidade.

Nessa linha interpretativa e de abordagem do literário, vemos que o ex-colonizado africano e também o brasileiro (em momentos diferentes, evidentemente) assumem uma atitude subversiva também no fazer literário, libertando-se do jugo canônico europeu, anunciando um separatismo estético, ideológico e, sobretudo, linguístico. Desvinculando-se da metrópole, política e esteticamente, as literaturas africanas e brasileira ganham autonomia cada vez mais sólida e tornam-se porta-vozes de uma consciência nacional. Essas literaturas emergem como possibilidades concretas de se considerar uma visão de mundo particular ou característica local específica não apenas como produtora de traços nacionais, mas também universais.

Nessa instância, é preciso reiterar que as sociedades que passaram pelo processo de dominação colonial têm características próprias com forças internas que interagem e modificam posturas frente às investidas coloniais. A leitura de textos desses espaços com pronunciadas particularidades deve, então, considerar esses locais com suas práticas e preocupações próprias: cada encontro colonial é/foi diferente e cada postura de resistência necessita ser localizada com precisão e analisada com especificidade dentro dos princípios gerais.

Apresentar textos de escritores africanos aos jovens estudantes não apenas cumpre o que está previsto na lei 11.645/08, mas possibi- 
lita o contato com um conjunto de práticas discursivas em que predomina a resistência às ideologias colonialistas, implicando, assim, em um alargamento do corpus com que a escola trabalha. Assim, incluir as chamadas literaturas emergentes bem como textos produzidos nas ex-metrópoles, reveladores de sentidos críticos sobre o colonialismo, contribui para a formação de um leitor mais atento aos elaborados jogos de poder no âmbito da sociedade em que está inserido.

A apropriação da língua portuguesa pelos diferentes escritores, macroquestão importante para as diferentes séries literárias como já mencionado, foi teorizada politicamente por Amílcar Cabral e desenvolvida na prática por escritores como os angolanos Luandino Vieira e Uanhenga Xitu, o moçambicano José Craveirinha e João Guimarães Rosa e Mario de Andrade, do Brasil, para citar apenas poucos exemplos.

Esses escritores produzem textos em que outras falas são incorporadas à tessitura textual, estabelecendo uma apropriação e reconstituição de uma língua do centro para engendrar o processo de sua integração e remodelação para novos usos.

Ensejam, enfim, marcar a separação do espaço do privilégio colonial e encontram, ainda, uma forma própria de dialogar com as tradições, em movimentos intertextuais que se interiorizam no corpo linguístico. Nesse sentido, recuperam-se a sintaxe, os ritmos híbridos da textualidade oral.

Sobre essa questão, vale trazer a reflexão sobre a língua portuguesa do escritor português Manuel Alegre que traduz de maneira singular as contradições inerentes ao processo:

É esse o poder da poesia. O poder da linguagem poética contra as múltiplas formas de barbárie. Eu creio que pela mediação da poesia os poetas fundaram os povos. E os povos fundaram a língua. E a língua fundou as nações. Como disse Holderlin: "o que fica os poetas o fundam." 
A língua portuguesa é uma língua de viagem e mestiçagem. Rio de muitos rios. E talvez pátria de várias pátrias. Sem esquecer que há o português da opressão e o português da libertação. O português das muitas tiranias e o português das várias resistências. A língua é a mesma. Mas não é a mesma. É una. Mas é diversa. Tanto mais ela quanto mais diferente. Tanto mais pura quanto mais impura. Tanto mais rica quanto mais mestiça. (ALEGRE, 2002, p. 52)

Nessa relação entre dominados e dominadores metaforizada nas figuras shakespearianas de Próspero e Caliban, outra importante questão, aludida por Boaventura de Sousa Santos, é que devido à condição periférica de Portugal, o Próspero lusitano é ele próprio um elemento calibanizado frente aos Prósperos europeus e essa condição será reduplicada de maneira dramática e violenta na relação com o mundo colonizado:

a ambivalência de identidade do colonizador mostra que este não se limita a conter em si a identidade do outro, colonizado por ele, mas também a do colonizador, enquanto colonizado por outrém: [...] a dupla ambivalência das representações afeta não apenas a identidade do colonizador, 'originalmente mestiço, calibanizado em casa pelos estrangeiros que o visitavam, cafrealizado em suas colónias, semicanibalizado nas colónias e ex-colónias de outras potências' como afeta também a do colonizado. (SANTOS apud LEITE, 2003, p. 18)

O hibridismo linguístico torna-se uma das características mais significativas da textualidade africana de língua portuguesa e não desprezível nas produções brasileiras, sobretudo a partir do século XX. Os textos constituídos em língua portuguesa demonstram como esse processo instituiu-se no interior da língua do colonizador, em um movimento de profunda transformação e resistência. Nesse sentido, vamos perceber que, sobretudo entre projetos literários de variados escrito- 
res angolanos e cabo-verdianos dos primeiros decênios do século XX, ocorre uma total sintonia com os pressupostos estéticos da $1^{\text {a }}$ fase do modernismo brasileiro. Não é por acaso que encontramos pronunciados pontos de convergências entre essas produções e os diálogos intertextuais que se apresentam constituem-se uma possibilidade única de unir pontas de sentidos que estão dispersos por meio de leituras no âmbito da escola.

Os modos de enunciação da textualidade oral em língua portuguesa e sua intermediação sofisticaram-se e diversificaram-se, apresentando diferentes tipos de apropriação no caso das africanas, como aponta Ana Mafalda Leite (2014): há escritores que seguem uma norma mais ou menos padronizada, como Pepetela e Luis Bernardo Honwana, mas há também aqueles que, com pronunciadas diferenças entre si, oralizam a língua portuguesa, como Boaventura Cardoso, Manuel Rui ou Ungulani Ba Ka Khosa. Há, ainda, os escritores cujo hibridismo assenta-se na recriação sintática e lexical por meio de recombinações linguísticas, como faz Mia Couto e, finalmente, aqueles bilíngues em cujos textos aparecem um certo interseccionismo linguístico, em que prolongamentos de frases se continuam em diferentes línguas, como é o caso de Uanhenga Xitu.

Com relação à literatura brasileira, sabemos que em sua formação era essencialmente europeia, importada com a conquista e submetida ao processo geral de colonização:

Levando a questão às últimas consequências, vê-se que no Brasil a literatura foi de tal modo expressão da cultura do colonizador, e depois do colono europeizado, herdeiro dos seus valores e candidato à sua posição de domínio, que serviu às vezes violentamente para impor tais valores, contra as solicitações a princípio poderosas das culturas primitivas que os cercavam de todos os lados. Uma literatura, pois, que do ângulo político pode ser encarada como peça eficiente do processo colonizador. (CANDIDO, 1987:165) 
A independência política de Portugal, em 1822, não significou independência cultural. Nesse panorama ainda de forte vinculação às matrizes metropolitanas, o romantismo representou o marco fundamental na busca por uma literatura nacional, firmando e afirmando os primeiros passos dados pelos poetas árcades. No período, a literatura era entendida como uma forma de afirmação nacional e de construção da pátria.

No entanto, é com a Semana de Arte Moderna, em 1922, que se dá o rompimento total com Portugal. Enquanto o romantismo procurava superar o domínio metropolitano, afirmando contra ele as particularidades literárias brasileiras, o modernismo de 22 desconsidera Portugal, que simplesmente deixa de existir como obstáculo a ser superado.

Segundo Antonio Candido (1980, p. 112), "o particularismo se afirma agora contra todo academismo, inclusive o de casa, que se consolidara no primeiro quartel do século XX, quando chegaram ao máximo o amaciamento do diálogo e a consequente atenuação da rebeldia."

A agenda estética do período procurará construir um novo nacionalismo, que irá assumir uma perspectiva crítica, em que se percebe a combinação de um tom entre anárquico e debochado. O percurso escolhido será o da celebração de nossas origens indígenas e africanas: nos povos autóctones e também no folclore, nos aspectos míticos e lendários da cultura popular, procura-se descobrir a essência do Brasil.

A questão do crescente afastamento do registro metropolitano da língua portuguesa e absorção dos falares em que predominam a oralidade e a coloquialidade também fazem parte da agenda estética do movimento e de seus precursores, como se pode notar no seguinte excerto do poema "Evocação do Recife", de Manuel Bandeira:

A vida não me chegava pelos jornais nem pelos livros

Vinha da boca do povo na língua errada do povo

Língua certa do povo

Porque ele é que fala gostoso o português do Brasil 
Ao passo que nós

O que fazemos

É macaquear

A sintaxe lusíada

A vida com uma porção de coisas que eu não entendia bem Terras que não sabia onde ficavam

(BANDEIRA, 1991, 106-107)

Os escritores engendram uma espécie de retorno às fontes primeiras de uma civilização original para ali encontrar algo que o colonialismo português não conseguira esmagar. Essa pesquisa de uma subjacente alma nacional só poderia ser realizada, no entanto, com o instrumental artístico da modernidade em um registro ousado, inventivo e até humorístico, com a linguagem das vanguardas. Dessa maneira, o Brasil seria modelo exemplar dessa síntese do primitivo e do inovador, ainda segundo Candido.

BRASIL

O Zé Pereira chegou de caravela

E preguntou pro guarani da mata virgem

— Sois cristão?

- Não. Sou bravo, sou forte, sou filho da Morte

Teterê Tetê Quizá Quizá Quecê!

Lá longe a onça resmungava Uu! ua! uu!

O negro zonzo saído da fornalha

Tomou a palavra e respondeu

- Sim pela graça de Deus

Canhém Babá Canhém Babá Cum Cum!

E fizeram o Carnaval

(ANDRADE: 1971, 169-170) 
A luta por uma nova linguagem, a descoberta do popular, o humor como forma crítica e traço distintivo do caráter brasileiro, a criação de uma utopia brasileira, em que se projeta uma sociedade de configurações anárquicas e sem repressões poderão ser observadas em variadas obras literárias inaugurais do período e o poema "Brasil" acima transcrito surge como tradução mais completa desse viés.

Atualmente, o projeto literário no Brasil parece ser uma questão já resolvida, inclusive com o reconhecimento do nosso "vínculo placentário" (CHAVES: 2005, p. 285) com as literaturas europeias. No entanto, os fundamentos da nacionalidade e a sua repercussão no processo cultural brasileiro permanecem como objeto de estudo, revelando que, na base dessa discussão, estão os laços estabelecidos pela condição colonial que determinou a sociedade brasileira.

Nesse percurso de possibilidades, a literatura afro-brasileira, duplamente marginalizada, pois é constituída pela cultura do (ex-)escravo subjugado e faz parte de uma literatura considerada periférica, desponta como o discurso apto a dar voz às margens da sociedade brasileira. Esse projeto literário pretende rebelar-se contra a concepção vigente da essência do belo como postura pretensamente universal do cânone literário hegemônico. O questionamento é, então, engendrado a partir de outras identidades, resultando no desejável desvelamento do reconhecido desprezo por essa produção por parte da academia e outras instâncias de canonização.

Por isso, trazer escritores negros com obras que explicitam essa condição para o âmbito da educação básica revela um posicionamento claramente ideológico porque se coloca contra silenciamentos e apagamentos históricos da tradição, da história e da cultura afro-brasileira e tem uma função inestimável para a formação dos jovens leitores. Por meio dessas novas vozes que se juntam àquelas já presentes no cânone pedagógico e abordadas dialeticamente, constroem-se diálogos com a tradição, permitindo aprofundar e problematizar questões do passado colonial que o Brasil necessita enfrentar de forma mais incisiva a fim de 
superar definitivamente impasses e dilemas. Essas escritas contribuiriam ainda para o combate ao racismo estrutural de nossa sociedade e para a desconstrução do mito do paraíso racial de nosso país.

Entre os variados exemplos de coletivos, instituições e/ou projetos literários e culturais à disposição do futuro professor, é importante destacar os Cadernos Negros, coletânea publicada pelo Movimento Quilombhoje, de São Paulo, desde 1978. A histórica publicação tem por objetivo primeiro desconstruir a tradição literária que exclui toda uma produção da população negra. Os autores que aderiram ao projeto sempre tiveram a preocupação precípua de refletir sobre o lugar ocupado pela literatura produzida por eles no cenário do sistema literário brasileiro.

Sem dúvida alguma é preciso que nossos jovens professores apropriem-se desse repertório, ainda muito disperso e marginalizado, para que possam efetivamente mudar projetos acadêmico-pedagógicos praticados nas escolas ainda ancoradas em concepções exclusivamente eurocêntricas.

Já com relação à literatura portuguesa, é possível construir um percurso analítico e pedagógico que possibilite a apreensão, por parte dos estudantes, da maneira como se constitui o pensamento imperialista por meio das imagens literárias em que sobressai um conceito problemático de alteridade. Essa postura pode ser devidamente equacionada com leituras comparativas de textos portugueses e das ex-colônias, que explicitam outros pontos de vista. Por outro lado, há de se destacar que, ao longo da historiografia literária portuguesa, não são poucos os autores e obras que abordaram e abordam a alteridade de perspectivas ideológicas críticas contrárias aos sistemas político e cultural vigentes, como o regime salazarista, por exemplo. Os chamados romances de guerra desnudaram o discurso monocórdico da ditadura, expondo com veemência os conflitos dos indivíduos frente às guerras no continente africano. Essas obras são marcadas por um tom eminentemente anti-heroico e anticolonialista, como é o caso de Jornada de África, de Manuel Alegre, Os cus de Judas ou Fado Alexandrino, de 
António Lobo Antunes, Partes de África, de Hélder Macedo ou, ainda, A costa dos murmúrios, de Lídia Jorge. A mitologia colonialista passa, assim, a ser objeto de crítica ferrenha por parte de muitos escritores.

Como tentamos demonstrar, o ensino de literatura tratado de uma perspectiva comparativa e tendo como horizonte a introdução de escritas africanas e afro-brasileiras oferece todo um instrumental para a plena apreensão, por parte do leitor, de práticas e representações sociais e históricas que se introjetam no texto literário e, assim, pode resultar em um projeto não apenas de emancipação dos indivíduos, mas sobretudo de reflexão crítica sobre os jogos de poder, da política e da sociedade, manifestando seu caráter transformador.

Nesse sentido, a literatura e a leitura no âmbito da educação básica proporcionam um exercício significativo de reflexão sobre si e sobre a coletividade, pois, ao tratar das grandes, mas também das miúdas, inquietações humanas, desvela o que há de mais profundo e obscuro na alma humana que constrói a sociedade. $O$ jovem professor e o estudante que emergem desse contexto certamente mais democrático de contornos heterogêneos e plurais estarão capacitados para engendrar uma escola realmente inclusiva, baseada em princípios de uma cidadania plena, que se desenha a partir da diversidade étnica e cultural que marca a sociedade brasileira.

\section{REFERÊNCIAS BIBLIOGRÁFICAS}

ABDALA JR., B. Literatura, história e política. São Paulo: Ed. Ática, 1989. ALEGRE, M. "Diversas são as falas" In: Arte de Marear. Ensaios. Lisboa: D. Quixote, 2002.

ANDRADE, O. Poesias Reunidas. Rio de Janeiro: Civilização Brasileira, 1971. BANDEIRA, M. Estrela da vida inteira. Rio de Janeiro: José Olympio Ed., 1991. CANDIDO, A. "Literatura de dois gumes" In: A educação pela noite \& outros ensaios. São Paulo: Ed. Ática, 1987, pp. 163-180.

CANDIDO, A. "Literatura e cultura de 1900 a 1945" In: Literatura e sociedade. São Paulo: Ed Nacional, 1980, pp. 109-138. 
CARVALHAL, T. F. Literatura Comparada. São Paulo: Ed. Ática, 2003, Coleção Princípios.

CHAVES, R. "Vida literária e projeto colonial e contradição no império português" In: Angola e Moçambique - experiência colonial e territórios literários. São Paulo: Ateliê Editorial, 2005, pp. 287-302.

FERREIRA, M. Literaturas africanas de expressão portuguesa. São Paulo: Ed. Ática. 1987.

FREIRE, P. \& MACEDO, D. Alfabetização - leitura do mundo/leitura da palavra. Rio de Janeiro: Paz e Terra, 1990.

HAMILTON, R. "A literatura dos PALOP e a teoria pós-colonial". São Paulo: Departamento de Letras Clássicas e Vernáculas/FFLCH/USP, 1999, v. 3, pp.12-23, Col. Via Atlântica.

LAJOLO, M. \& ZILBERMAN, R. A formação da leitura no Brasil. São Paulo: Ed. Ática, 2003.

LEITE, A. M. "Literaturas africanas e pós-colonialismo" In: Literaturas africanas e formulações pós-coloniais. Lisboa: Colibri, 2003, pp. 9-40.

LEITE, A. M. "Empréstimos da oralidade na produção e crítica literárias africanas" In: Oralidades \& Escritas nas literaturas africanas. Lisboa: Edições Colibri, 2014.

ORLANDI, E. P. A leitura e os leitores. Campinas: Pontes, 1998.

PADILHA, L. "Da construção identitária a uma trama de diferenças um olhar sobre as literaturas de língua portuguesa". In: Revista Crítica de Ciências Sociais, 73. Coimbra, 2005.

RAMA, A. "Os processos de transculturação na narrativa latino-americana" In: AGUIAR, F. W. \& VASCONCELOS, S. G. T. (org.). Angel Rama - Literatura e cultura na América Latina. São Paulo, Edusp, 2001.

RUI, Manuel. "Eu e o outro - O Invasor ou Em poucas três linhas uma maneira de pensar o texto" In: MEDINA, C. Sonha Mamana África. São Paulo: Epopéia, 1987.

SAID, E. W. Cultura e imperialismo. São Paulo: Companhia das Letras, 1995. SANTILLI, M. A. Paralelas e Tangentes entre as Literaturas de Língua Portuguesa. São Paulo: Via Atlântica, 2003. 